\title{
Heredity-environment interaction in brain extract transfer in highly inbred mice'
}

\author{
A. B. CARRAN AND CAROLYN P, NUTTER \\ UNIVERSITY OF ALBERTA, EDMONTON
}

Donor mice of two strains were trained to approach a food cup when a click was sounded. Extract from the brains of the trained doitors and from untrained control donors was injected into untrained mice. Recipients of same-strain trained or different-strain untrained extract approached the cup faster than those receiving either same-strain untrained or diferent-strain trained extract. Activity during a 15-sec. interval between clicks was lowest for recipients of same-strain trained extract

Babich, Jacobson, Bubash, \& Jacobson (1965) and Fjerdingstad, Nissen, \& Røigaard-Petersen (1965) have obtained better performance from rats receiving injections of extract from the brains of trained rats than from rats receiving extract from untrained rats. The purpose of the present study of transfer in genetically standardized mice was to explore the possibility that the transfer effect might vary with the degree of genetic homogeneity existing between donor and recipient animals.

Method

Subjects. Thirty-two $\mathrm{C} 3 \mathrm{H} / \mathrm{HeJ}$ and $32 \mathrm{C} 58 / \mathrm{J}$ male mice, $27 \pm 3$ days of age, were received from Jackson Laboratory, each shipment containing 16 mice of each strain.

Procedure and Apparatus. When aged 35 days, eight experimental and eight control donor mice of each strain were begun on daily food deprivations of $9.5 \mathrm{hr}$. which were extended to $12 \mathrm{hr}$. for days $39-40$ and to $16 \mathrm{hr}$. for days 41-47. Lighting was continuous and temperature was maintained within the limits $75-78^{\circ}$ by forced air conditioning.

The apparatus consisted of a plyboard box, $18 \mathrm{~cm}$ square with walls $15 \mathrm{in}$. high. The floor was of $1 / 4 \mathrm{in}$. wire mesh, and was divided into nine $6 \times 6 \mathrm{~cm}$ squares by underslung red wiring. The box was covered by a removable transparent plastic top. One corner of the box contained a $1 \times .75 \mathrm{in}$. food cup, .5 in. deep with the rim located $3.3 \mathrm{~cm}$ above the floor. A $3 \times 1$ in. piece of fine wire mesh was strung vertically above the food cup to deflect pellets into the cup. A LehighValley pellet dispenser which produced a loud click when activated was attached to the outside of the wall adjoining the food cup and water was continuously available from a spout diagonally opposite the food cup.

On days $43-47$, just before feeding, experimental donor mice were placed alone in the apparatus for $15 \mathrm{~min}$. On days 46 and 47 , they were given two clickfood pairings, one at the beginning and one at the end of the adaptation session. On days 48-51 and for one session in the morning of day 52, experimental donors were given $20 \mathrm{~min}$. training sessions. Ss were trained to approach the food cup in a manner described by Babich et al (1965) except that they were only given 35 reinforcements at most during a single session, and were given $20 \mathrm{mg}$ pellets. An attempt was made to avoid producing superstitious behavior. Four training sessions per day separated by 160-min. of deprivation were given, the first session beginning at the time when $\mathrm{S}$ had previously been given food in its home cage at the end of its period of deprivation. If Sdid not consume its full quota of pellets it was allowed to make up the difference in its home cage. After the fourth session Ss were given Purina Chow in their home cages for $1 \mathrm{hr}$. At the end of training the Ss promptly and reliably approached the food cup when a click was sounded, but achieved only limited inhibition of the approach during the interval between clicks. Untrained control donors remained in their home cages where they were fed at times and in amounts equivalent to the experimental donors.

One hr. after the last training session material was extracted from donor brain tissue anterior to the caudal superior colliculus and rostral pons, but excluding the olfactory bulbs, in the manner described by Babich et al (1965) except that it was necessary that four brains of the same strain and level of training be batched together because of their small size. Since four C58/J brains as prepared weighed a total of $1.0 \mathrm{gm}$ the same amounts of material employed in the study of Babich et al were used. Yields were dissolved in $1.7 \mathrm{ml}$ saline and $.05 \mathrm{ml}$ was drawn from each batch for optical density measures of RNA. Within $1 \mathrm{hr}$. of extraction the remaining extract was injected in equal portions into recipient mice. Eight recipients received extract from trained donors, four from donors of the same strain (Group $\mathrm{S}^{+}$) and four from donors of the different strain (Group $\mathrm{D}^{+}$). The remaining eight recipients received extract from untrained donors, four from the same strain (Group $\mathrm{S}^{-}$) and four from the different strain (Group $\mathrm{D}^{-}$). In each of the four groups, two recipients were $\mathrm{C} 3 \mathrm{H}$ mice and two were $\mathrm{C} 58 / \mathrm{J}$ mice. All injections were given intraperitoneally via a $1.5 \mathrm{~cm}, 27$ gauge needle.

For five days prior to injection the 16 recipients were given daily $15 \mathrm{~min}$. adaptation sessions. During each session the click was sounded twice without food being given. Food powder was sprinkled lightly over the floor of the apparatus. Ss spent considerable time in the vicinity of the food cup. There seemed to be a marked tendency for Ss to return to it when a click was sounded during early adaptation. The recipients were deprived 
of food $12 \mathrm{hr}$. before injection. Four hr. after injection a recipient was given the first of four identical testing sessions each lasting approximately $8 \mathrm{~min}$. and with the interval between the beginning of each session set at $4 \mathrm{hr}$. Throughout testing a mouse was deprived of food except that it was given two $45 \mathrm{mg}$ pellets in its home cage immediately after a session. Four experimenters were used in testing: $\mathrm{E}_{1}$, blind to the level of education and strain of donor, waited for at least 2 min. after a recipient had been placed in the box and until it seemed unlikely that it would soon return to the cup. She then for five trials, each separated by at least a minute, sounded a click and recorded the latency for the mouse to stick the tip of its nose over an edge of the square containing the food cup; $E_{2}$, similarly blind, measured activity by counting the number of squares $S$ entered or traversed during a $15 \mathrm{sec}$. interval beginning $30 \mathrm{sec}$. after a click; $\mathrm{E}_{3}$, also blind, recorded latencies for half the mice and activity for the remainder, solely for estimating reliabilities. A fourth $\mathrm{E}$ served as a timer and silently signalled Es recording activity when to start and stop. All Es used silent stopwatches.

The procedure was repeated with mice from the second shipment, and the data combined for analysis. Results

Ribonucleic acid estimates were in the range .67 to $1.18 \mathrm{mg}$ per $\mathrm{gm}$ of tissue. ${ }^{2}$

Since the mice were active in the box and since the strains had different rates of locomotion it had been decided before the random assignment of conditions to recipients to use only the two fastest approaches of each session. Estimates of observer reliability for the average latency and activity scores were, respectively, $r=.96$ and $r=.99$. The means of fastest approaches and the mean activity scores for 15-sec. intervals are shown in Table 1. Adopting the notation of Table 1, it is seen that both $\mathrm{S}^{+}$and $\mathrm{D}^{-}$mice had lower latencies than either $\mathrm{S}^{-}$or $\mathrm{D}^{+}$mice. Although the low latency $\mathrm{D}^{-}$mice also had the highest activity scores, the $\mathrm{S}^{+}$mice had even lower latencies but showed less activity than any other group.

Analysis of variance was performed on the latency data. There was a significant interaction of strain of donor, strain of recipient and level of training $(F=7.09$, $\mathrm{df}=1 / 24, \mathrm{p}<.02$ ), indicating that the transfer effect depended upon the degree of homogeneity of hereditary factors in donor and recipient animals. The main effect of recipient-strain was the only other significant effect $(\mathrm{F}=4.71, \mathrm{df}=1 / 24, \mathrm{p}<.05)$.
Table 1. Latency of Two Fastest Approaches per Session and Activity in 15 Seconds ${ }^{a}$

\begin{tabular}{lccrrr} 
Recipients & \multicolumn{4}{c}{ Mean Latency } \\
& $\mathrm{D}^{+}$ & $\mathrm{S}^{+}$ & $\mathrm{D}^{-}$ & $\mathrm{S}^{-}$ \\
\hline C3H & 7.68 & 5.16 & 5.65 & 6.93 \\
C58 & 5.39 & 3.81 & 3.75 & 6.00 \\
Mean & 6.53 & 4.49 & 4.70 & 6.47 \\
& \multicolumn{5}{c}{} \\
\hline C3H & \multicolumn{4}{c}{ Mean Activity } \\
C58 & 4.36 & 4.03 & 4.75 & 4.80 \\
Mean & 6.85 & 6.54 & 8.50 & 3.05 \\
\hline
\end{tabular}

$a-S$ signifies same-strain donor, $D$ signifies different-strain donor, + indicates donor was trained, - indicates donor was untrained.

\section{Discussion}

If it is assumed that $\mathrm{D}^{+}$mice suffered disorganization but retained some "cerebral dominance" and that $\mathrm{D}^{-}$ mice lost habituation to the click stimulus due to the effect of brain-extract injection, it is possible to explain the present results for $\mathrm{S}^{+}$and $\mathrm{S}^{-}$mice as an instance of positive transfer involving molecular memory coding but other interpretations are possible and in view of the latency and activity scores of the $\mathrm{D}^{-}$mice it appears that positive transfer on the basis of trained extract may not be a general, species-wide effect. If firm progress is to be made in the area of brain extract research, careful attention must be given to the reduction of genetic as well as environmental sources of error variance and to choices made with respect to each of these variables.

\section{References}

Babich, F. R., Jacobson, A. L., Bubash, S., \& Jacobson, A. Transfer of a response to naive rats by injection of ribonucleic acid extracted from trained rats. Science, $1965,149,656$.

Fjerdingstad, E. J., Nissen, F., \& Róigaard-Petersen, H. H. Effect of ribonucleic acid (RNA) extracted from the brain of trained animals on learning in rats. Scand. J. Psychol., 1965, $6,1-6$.

\section{Notes}

1. The present research was partially supported by a Canadian Public Health Research Grant DPH 33,608-7-82 and by a National Research Council of Canada Grant APT-105, both to Professor J. R. Royce.

2. The authors are indebted to Dr. B. G. Lane for training in the extraction procedure, for facilities used in the biochemical procedures and for furnishing estimates of the yields of RNA plus phenol. 